\title{
Experimental study on LCZ Temperature field of Multi-layered Porous Media Salt Gradient solar Pond
}

\author{
Hua Wang \\ School of Mechanical and Power Engineering \\ Henan Polytechnic University \\ Jiaozuo, China, 15039138423 \\ wonghua78@gmail.com
}

\begin{abstract}
This paper presents the concept of multi-layered porous media salt gradient solar pond (MP-SGSP). The thermal behavior has been analyzed and compared with the single-layer porous media solar pond. The experiments show that: the heat storage layer (LCZ) temperature rising rate of MP-SGSP with slag plus glass balls was significantly higher than that of singlelayer porous media solar pond with slag only, and temperature drop rate was slightly lower than single-layer porous media solar pond.
\end{abstract}

Keywords-multi-layered porous media; solar pond; LCZ temperature field

\section{INTRODUCTION}

Solar pond is a kind of salt pond with a certain concentration gradient, and it is a solar heat utilization system not only by collecting but also storage solar energy. Structure of traditional salt gradient solar pond is simple and low cost, as is shown in Figure 1.

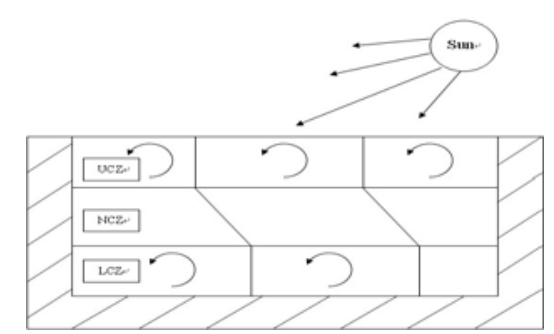

Fig.1 Three-tier model diagram of traditional solar pond

It is mainly composed of three layers: the surface is a thin layer of fresh water, called upper convective layer (UCZ); the lowest level is brine, called heat storage layer or lower convective layer (LCZ); upper convective zone and the lower convective layer is separated by non-convective layer (or called salt gradient layer or NCZ), and salinity of this layer increases in turn from top to bottom, used to block or reduce heat of lower convective layer losing to the upper surface. Because of its heat storage, solar pond has an important potentiality for development in solar thermal utilization. But turbidity of water[1,2], the wall design[3], keeping of salt gradient[4,6], wall insulation as well as environment and climate will have an important impact on the solar pond temperature, so LCZ temperature of the traditional solar pond is difficult to achieve a higher temperature. Therefore, increasing LCZ temperature of the solar pond has important significance.

This work is supported by Henan Provincial Key Discipline Project of Fluid Mechanics (507907) and Henan Provincial Characteristics Professional Project of Thermal Energy and Power Engineering (508057).

\author{
Feiling Shen \\ School of Mechanical and Power Engineering \\ Henan Polytechnic University \\ Jiaozuo, China, 13723178502 \\ shenfeiling@126.com
}

The porous media solar pond is a four-layer model and added a layer of porous media at the bottom of the traditional solar pond. Porous media has a smaller thermal diffusivity with low thermal diffusion coefficient which has good thermal insulation performance. Sun Wence[7,9]proved that adding porous materials at the bottom of solar pond is favorable to raise LCZ temperature. Porous media is suitable to be selected as the color black and low thermal diffusion coefficient materials, so cheap factory wastes--boiler slag[8] is a good alternative material, however we can reasonably infer that adding too much boiler slag in solar pond leads to that the bottom boiler slag can not receive solar radiation, resulting in a waste of porous media to a certain extent, and LCZ still not reach the highest value.

For the shortcomings of the traditional solar pond, the concept of MP-SGSP is presented. The bottom of MP-SGSP is added two or more porous media layers, using different porous media properties to achieve the best thermal storage effect. Its advantages are analyzed as follows:

(1) Darker porous media has strong ability to receive thermal radiation and weak ability to reflect heat radiation, which is conducive to the increase of LCZ temperature while glass balls have up to $90 \%$ transmittance, and reflect about $8 \%$ while absorb about $2 \%[10]$, so plus a layer of transparent glass balls above dark boiler slag, which can not affect the underlying dark porous media on the absorption of solar radiation on the basis of increased thickness of the porous media, to ensure the maximum thickness of the porous media in the solar pond, to the greatest extent accepted thermal radiation, a feature that is superior to single-layer porous media.

(2) Total storage heat of MP-SGSP with slag plus glass balls and single-slag both can be calculated by:

$$
\mathrm{E}_{\text {solar }}=\overline{\mathrm{C}} \mathrm{m} \Delta \mathrm{T}
$$

Where $\mathrm{E}_{\text {solar }}$ is the constant total heat of LCZ because of the constant area A of the solar pond, $\overline{\mathrm{C}}$ is the average specific heat of porous medium $\left(\mathrm{kJ} / \mathrm{kg} \cdot{ }^{\circ} \mathrm{C}\right), \mathrm{m}$ is the quality of the porous media $(\mathrm{kg}), \Delta \mathrm{T}$ is temperature of LCZ $\left({ }^{\circ} \mathrm{C}\right)$. Table 1 gives the thermal properties of the materials. The specific heat capacity of glass balls is less than that of slag, and the average specific heat capacity of slag and glass balls is less than that of single-slag. If average specific heat capacity of slag plus glass balls is lower, LCZ temperature T of MP-SGSP is higher than 
the temperature of the single-layer solar pond by the premise of ensuring the same quality of porous media.

(3) Boiler slag used in the experiment is likely to make solar water more turbid, and therefore adding a layer of smooth glass balls can ensure maximum clarity of solar water and its thermal storage capacity.

TABLE 1 PHYSICAL PROPERTIES OF BOILER SLAG AND GLASS BALLS

\begin{tabular}{c|c|c|c|c}
\hline Materials & $\begin{array}{c}\text { Density } \\
\mathrm{kg} / \mathrm{m}^{3}\end{array}$ & $\begin{array}{c}\text { Thermal } \\
\text { conductivity } \\
\mathrm{W} /(\mathrm{m} \cdot \mathrm{k})\end{array}$ & $\begin{array}{c}\text { Specific } \\
\text { heat } \\
\mathrm{kJ} /(\mathrm{kg} \cdot \mathrm{k})\end{array}$ & $\begin{array}{c}\text { Thermal } \\
\text { diffusivity } \\
\mathrm{m}^{2} / \mathrm{s}\end{array}$ \\
\hline Slag & 1500 & 0.29 & 0.96 & $2.01 \times 10^{-7}$ \\
\hline $\begin{array}{c}\text { Glass } \\
\text { balls }\end{array}$ & 2800 & 0.76 & 0.8 & $3.8 \times 10^{-7}$ \\
\hline
\end{tabular}

\section{EXPERIMENTAL MATERIALS AND PROGRAMS}

\section{A. Experimental Materials}

The length, width and height of the solar pond used in experiment which is stainless steel materials are all $40 \mathrm{~cm}$. There is $3 \mathrm{~cm}$ thick insulation layer outside solar pond. Low convective layer is $15 \mathrm{~cm}$, salt gradient layer is $15 \mathrm{~cm}$, and upper convective layer is $10 \mathrm{~cm}$ with water perfusion. Heat storage layer is prepared with the saturated solution. Firstly, injected into $15 \mathrm{~cm}$ clean water, pour into the desired salt (the amount necessary calculated according to the volume of water) and stir in order to promote the dissolution of the salt. Put a layer of plastic film on the heat storage layer, and then gently pour the brine of lower salt concentration, use the same method to establish three salt gradient layers, making salinity reduce by $5 \%$ from the bottom layer by layer. Upper convective layer is filled with fresh water.

Experimental materials are factory waste boiler slag and inexpensive glass balls. Respectively wash and filter slag and glass balls, where particle diameter of slag is no more than $2 \mathrm{~cm}$, glass ball diameter is $2 \mathrm{~cm}$. Two combinations:

(1) Single slag: $6 \mathrm{~cm}$;

(2) Dark slag and transparent glass balls: dark slag $4 \mathrm{~cm}$, transparent glass ball $2 \mathrm{~cm}$, which slag at the bottom while glass balls in the upper.

Respectively, evenly spread two combinations of (1) and (2) at the bottom of the solar pond.

\section{B. The Experimental Procedure}

In the first set of experiments, only $6 \mathrm{~cm}$ boiler slag spread at the bottom of the solar pond, which is heated for 10 minutes by universal furnace, the power of which is $1000 \mathrm{w}$, then natural cooling with temperature sensor of an automatic weather station system to record the temperature of different depths in the solar pond changed with time. Four temperature sensors were put into the solar pond, in turn arranged vertically in the solar pond, respectively $4 \mathrm{~cm}, 8 \mathrm{~cm}, 12 \mathrm{~cm}, 20 \mathrm{~cm}$ from the bottom of the solar pond. Turn on the automatic weather station recording four measuring point temperature.

With the same salt gradient, in the second set of experiments, the $4 \mathrm{~cm}$ dark slag were spread evenly at the bottom of the solar pond, and the upper transparent glass ball is $2 \mathrm{~cm}$.With the same power, heating the same time, recorded data.

Experimental data was derived from the automatic weather station and processed to calculate the heat storage capacity of different porous media solar ponds to find out the best combination of experimental materials.

\section{EXPERIMENTAL RESULTS AND DISCUSSION}

As is shown in Figure 2, the LCZ temperature of slag and slag plus glass balls at different depths from the bottom of the solar pond has been presented. From Figure 2(a) blank experiment with saline only, it can be seen temperature at different depths rise uniformity, and different depth temperature is basically the same upward trend. Figure 2(b) is the single-slag experiment. Because the experimental solar pond is heated by furnace to simulate solar radiation, the temperature of lower layer rise more fast, and we can see the upward trend of different depths temperature is significantly different, and closer to the bottom of solar pond, the slower downward trend; Figure 2(c)is multi-layered experiment of slag plus glass balls, and we can see that the different depths temperature distribution is greater, and closer to the bottom of solar pond, the temperature upward trend significantly higher.

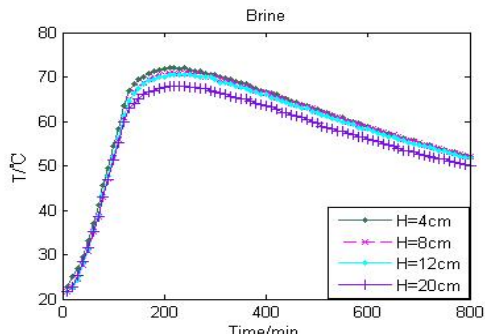

(a)

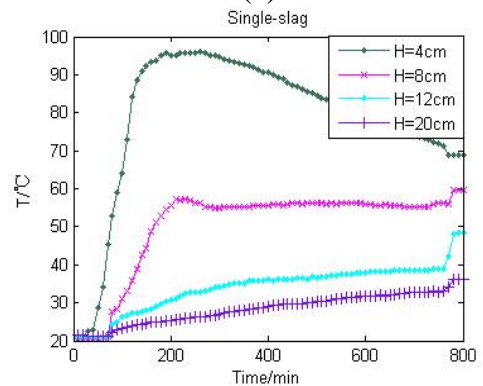

(b)

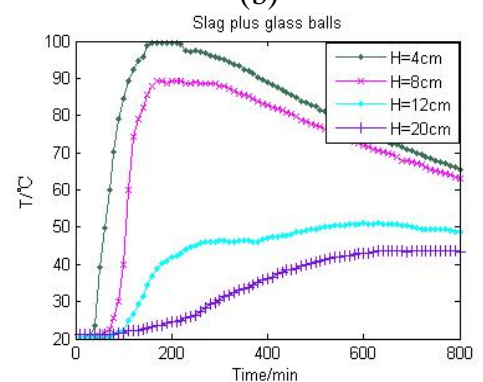

(c)

Fig.2 Temperature contrast of brine, slag and slag plus glass balls at different depths from the bottom of the solar pond 
As is shown in Figure 3, different experimental data with the same depth was compared. Figure 3(a) is temperature contrast of $4 \mathrm{~cm}$ from the bottom of solar pond, and we can see with the same heating time, temperature of slag plus glass balls rise faster, but the downward rate is slightly lower than the slag experiments; Figure 3(b) is temperature contrast of $8 \mathrm{~cm}$ from the bottom of solar pond, you can clearly see that within a minute or two at the beginning of experiment the rise rate of slag plus glass balls experiment is lowest, followed by slag experiment, but as the experiment continues, rising rate of slag plus glass balls experiment is significantly higher than slag experiments.

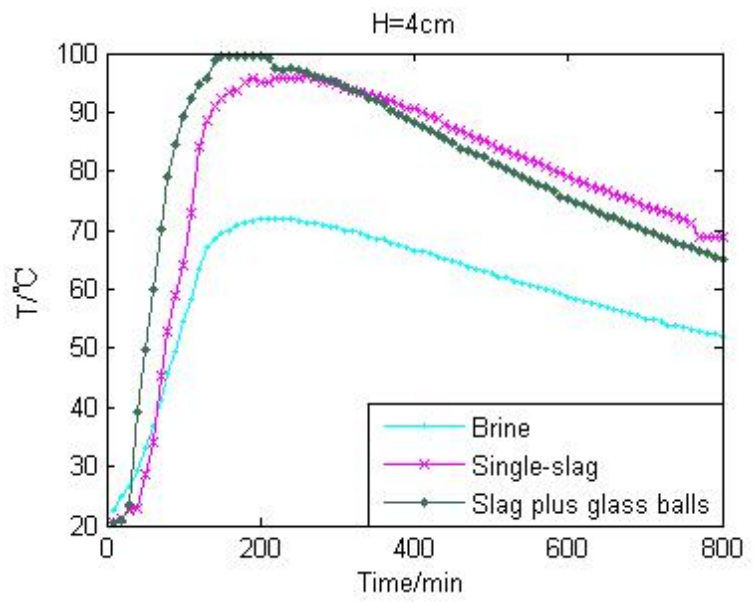

(a)

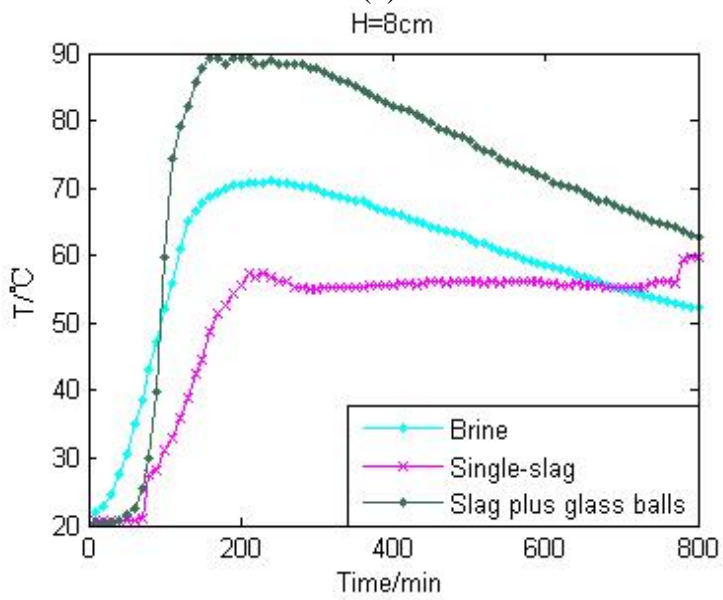

(b)

Fig.3 Temperature development of different depths from the bottom of the solar pond

As is shown in Figure 4, the fastest rise rate of temperature was slag plus glass ball experiment at $4 \mathrm{~cm}$ from the bottom of the solar pond, and followed by slag plus glass ball experiment at $8 \mathrm{~cm}$ from the bottom of the solar pond, and followed by slag experiment at $4 \mathrm{~cm}$ from the bottom of the solar pond; the fastest downward rate of temperature was black experiment with brine only. But the downward rate of the slag plus glass balls experiment was slightly lower than single-slag experiment.

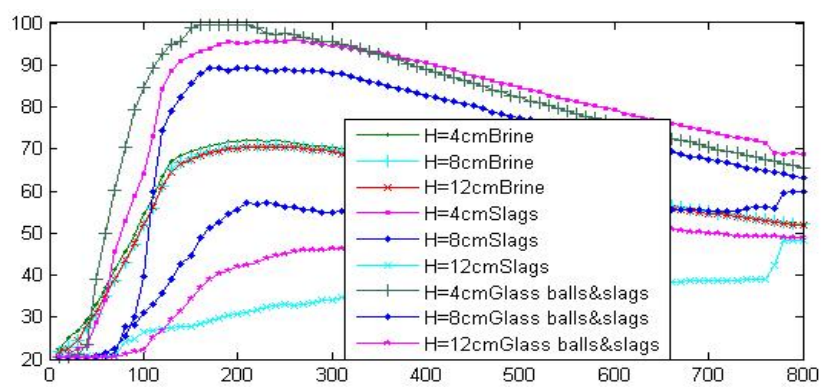

Fig.4 Temperature development of different depths and different media

\section{CONCLUSIONS}

(1)Within a minute or two at the beginning of the experiment, the rising rate of slag plus glass balls experiment was lowest, followed by the single-slag experiment. The fastest rising rate of temperature was black experiment with brine only;

(2)As the experimental time increases, the rising rate of slag plus glass balls experiment was significantly higher than the black experiment with brine only and single-slag experiment. The fastest rise rate of temperature is slag plus glass ball experiment at $4 \mathrm{~cm}$ from the bottom of the solar pond;

(3)The downward rate of the slag plus glass balls experiment was slightly lower than single-slag experiment. The fastest downward rate of temperature was black experiment with brine only;

(4) Both in black experiment with brine only, single-slag experiment and slag plus glass balls experiment, closer to the bottom of solar pond, the upward trend of temperature significantly higher.

\section{REFERENCES}

[1] J. Wang and J. Seyed-Yagoobi, "Effect of water turbidity on thermal performance of a salt-gradient solar pond," in Vol.54 of Solar Energy (1995), pp.301-308

[2] LUH and SWIFT A H P, “Advancements in salinity gradient solar pond technology based on sixteen years of operational experience," in Solar Energy Eng, (2004), pp.126

[3] Liexian Xie, "Research on thermal collector and storage performance of small solar pond,” in Vol.30 of Guangxi Forestry Science (2001), phase 3, pp.129-131.

[4] Wence Sun and Yongping Zhou, "Study of salt-pan solar pond," in Vol.43 of Journal of Dalian University of Technology (2003), phase 2, pp. 176-180

[5] Hull J R, "Maintenance of brine transparency in salinity gradient solar ponds, “ in Vol.112 of Journal of Solar Energy Engineering (1990), phase 5, pp. 65-69.

[6] Hua Wang et al, "Nonlinear dynamic behavior of non-convective zone in salt gradient solar pond,” in Solar Energy 85 (2011), pp. 1745-1757

[7] Wence Sun et al, “ Experimental study on effect of the porous medium on the thermohaline proliferation of solar pond,” in Vol.50 of Journal of Dalian University of Technology (2010), phase 1, pp.46-51

[8] Hua Wang, in: edited by Vol. 30 of Acta Energiae Solaris Sinica (2009) ( in Chinese) , issue 7, pp.905-910

[9] Hua Wang, in: Experiment and numerical simulation of a seawater solar pond, edited by International Conference on Power Engineering (2007)

[10] Domestic and foreign non-metallic materials manual, published by Jiangsu Science and Technology Press (2006) 